All letters are subject to editing and may be shortened. Letters should be sent to the BJGP office by e-mail in the first instance, addressed to

journal@rcgp.org.uk (please include your postal address). Alternatively, they may be sent by post as an MS Word or plain text version on CD or DVD. We regret that we cannot notify authors regarding publication. Letters not published in the Journal may be posted online on our Discussion Forum. For instructions please visit: http://www.rcgp.org.uk/bjgp-discuss

\section{Frailty in old age}

Jan De Lepeleire et $\mathrm{a}^{1}$ have highlighted a very important area in the assessment of older patients. I fully endorse their emphasis on the ways that frailty may be reversed. However, frailty can be a prognostic indicator that should alert us to other issues, such as effective planning for end-of-life care. Frailty can be useful as a component in the identification of an irreversible decline.

Patients and relatives often need clear information about this state, that is also crucial for carers (professional or laypersons). At the end of life, frailty increases and may alert us to:

- the need to stop active or inappropriate interventions;

- to plan the place of end-of-life care;

- to ensure proper symptom control;

- to stop the revolving door cycle of fruitless admissions that can mar the final days/weeks of some older patients;

- to prepare relatives and carers that death is approaching; and

- to help relatives/carers prepare for death and appropriate grieving.

I was a little disappointed that the paper did not discuss this area in more detail. We are already moving away from the idea that palliative care/terminal care only applies to malignant conditions.

Death is, at some point, inevitable. Part of our duty to patients and carers is to ensure that death is managed appropriately and with dignity. We need better understanding of when frailty is irreversible as well as an optimistic and rehabilitative approach to reversible factors.

\section{Avril Danczak,}

GP, The Alexandra Practice,

365 Wilbraham Road, Whalley Range,

Manchester, M16 8NG.

E-mail: avril@doctors.org.uk

\section{REFERENCE}

1. De Lepeleire J, Iliffe S, Mann E, Degryse JM. Frailty: an emerging concept for general practice. $\mathrm{Br} J \mathrm{Gen}$ Pract 2009; 59(562): e177-e182.

DOI: 10.3399/bjgp09X453846

\section{Authors' response}

We agree with Avril Danczak that palliative care for frail older people is an important issue, but our purpose was different. We wanted to reframe frailty and pre-frailty as tractable problems, even if temporary reversal of frailty is difficult in the current environment in many countries in primary care. The challenge is then to think about interventions to increase capability and function rather than provide prosthetic replacements for them.

Nevertheless, it is important to know when frailty becomes intractable. This is problematic, especially when cognitive impairment is severe and impedes communication. The predictions that practitioners make about the course of frailty are often wrong, with both underestimation and overestimation of mortality risk.

End-of-life care for frail older people has also tended to focus on what should be withheld, rather than on what should be done. ${ }^{1}$ As Danczak says, the lack of clarity about prognosis and best practice in palliation can result in care that can easily fall below acceptable standards, and inappropriate emergency admissions to hospital.

\section{Jan de Lepeleire,}

Katholieke Universiteit Leuven, General Practice, Kapucijnenvoer 33 - blok j - bus 7001, Leuven, 3000 Belgium.

E-mail: jan.delepeleire@med.kuleuven.be

Steve IIIffe,

University College London, Department of Primary Care, London.

\section{Jean Marie Degryse,}

Université Catholique de Louvain, CAMG, Brussels, 1200 Belgium.

\section{Eva Mann}

Habsburgerstrasse 1, Rankweil, 6830 Austria.

\section{REFERENCE}

1. Goodman C, Evans C, Wilcock J, et al. End of life care for community dwelling older people with dementia: an integrated review. Int J Geriatric Psychiatr 2009 (in press).

DOI: 10.3399/bjgp09X453855

\section{Music in the waiting room}

Music is common in the GPs' waiting room despite conflicting evidence of its effect on patients' anxiety, ${ }^{1,2}$ and stress. ${ }^{3}$ In primary care Zalewsky, ${ }^{4}$ reports that $88 \%$ of patients find music improves their mood. Additionally, Kabler reports that in the UK $83 \%$ find it relaxing. 'Muzak', can provoke strong feelings. ${ }^{6}$ These studies report small numbers and have no comparator, and none of them report views of healthcare staff. We aimed to explore the perceptions held by patients 